\title{
The Beginnings of Computer Use in Primary and Secondary Education in Spain
}

\author{
Javier Osorio and Julia Nieves \\ Universidad de Las Palmas de Gran Canaria, Spain \\ \{javier.osorio, julia.nieves\} @ulpgc.es
}

\begin{abstract}
During the late 1970s, Spain began its political transition from a dictatorial regime to a democratic one. In the 1980s, the country evolved economically and socially in a process that was speeded up by its incorporation into the European Union. The early 1990s witnessed Spain's entrance into the international arena, culminating with the successful organization of the Olympic Games in 1992. During these effervescent years, transformations in almost every facet of the country's make-up also affected the educational field. In this evolving situation, microcomputers arose and were incorporated into the educational space. At the end of the 1970s, the presence of computers at the primary and secondary education levels was practically non-existent. During the 1980s, an intense governmental effort took place to massively introduce computers in classrooms through institutional plans and policies. The results were uneven, and the greatest benefit was possibly observed in the use of the computer to manage schools, an aspect that experienced great development but was not equaled by the use of the computer to introduce new educational methodologies.
\end{abstract}

Keywords: Primary and secondary education, computers, educational history, Spain, 1980s.

\section{Introduction}

The second half of the 1970s was characterized by important changes in Spanish society. After the death of the dictator in November 1975, there was a progressive political transformation toward a democratic regime that culminated in 1978 with the passing of the Constitution that continues to be the basis for the Spanish legislative framework. This Constitution signified the normalization of political parties and defined a territorial model of the country based on a high level of political autonomy by its regions. These regions eventually created their own regional parliaments and governments with complete decision-making capacity in certain areas. Thus, except for defense and foreign policy, the majority of the decisions were gradually becoming decentralized, so that each region, also called autonomous communities, had the capacity to make decisions, while respecting the agreements established in the Constitution. 
Education participated in these political changes and was one of the decision-making areas whose management was entrusted to regional governments. The educational decentralization was carried out in a transitory way. At the beginning of the 1980s, six autonomous communities took control of their own educational management (Catalonia, Galicia, the Basque Country, Andalusia, The Canary Islands and the Valencian Community), while the other 11 postponed the transference of competences in educational matters and remained under the management of the central Spanish government through the Education Ministry. In other words, for most of this decade, the model for educational management was based on the coexistence between an institution that managed the majority of the national territory in educational matters (Education Ministry) and six other regional institutions with competences only in their own regions (Boards of Education). Throughout the 1990s, the educational administration became completely decentralized, and each region came to be responsible for managing education in their territorial setting. Figure 1 shows a map of the Spanish autonomous communities.

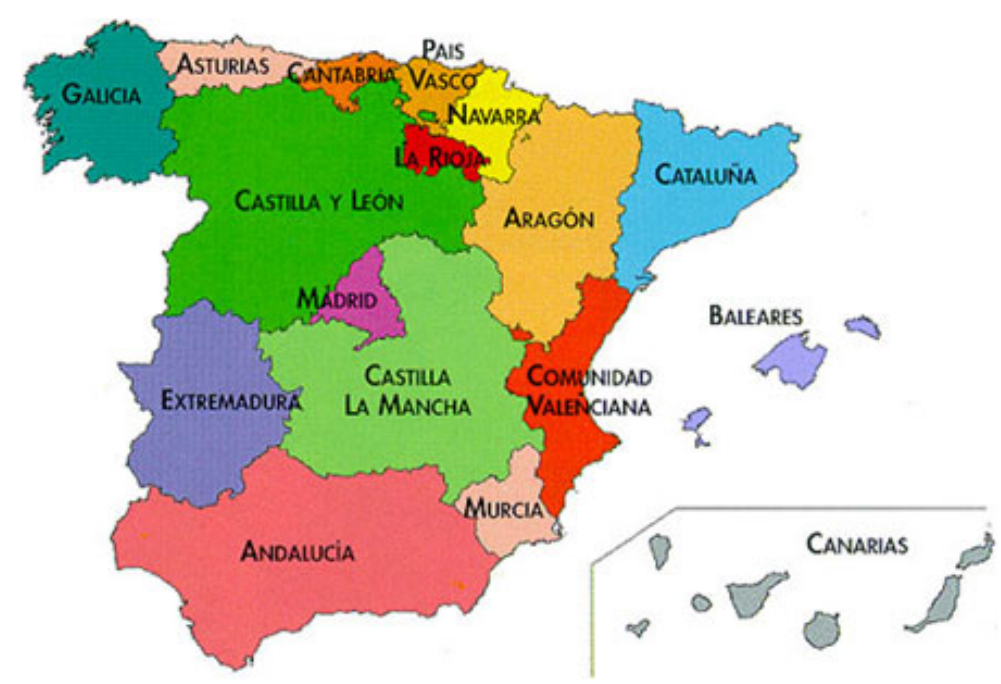

Fig. 1. Spanish autonomous communities as defined in the Constitution of 1978

Micro-computers and personal computers burst into this scenario, especially from 1981 on, with the appearance of the compatible IBM-PC. This device rapidly found a place in all areas of economic and professional activity. The educational field has traditionally been a step behind the economic arena in incorporating computers into its functioning. However, the wave of the PCs was so intense that the education sector rapidly became immersed in incorporating these devices in their schools. Nevertheless, the lack of computer resources and personnel trained in their use in the primary and secondary schools was a strong impediment to carrying out initiatives for the adoption of information technology by individual schools.

The exceptions consisted of initiatives by teachers who voluntarily took their own computers into the classroom, more for demonstration purposes than as a work tool. 
Those responsible for the schools were increasingly aware of the importance that this type of technology could have in the learning process, but they were unable to make large scale implementation plans due to a lack of economic capacity and, above all, the scant or non-existent willingness of many teachers to change their teaching methods and receive training in the use of these devices. During the 1980s, computer science was not an obligatory subject in primary and secondary schools. This was not the case in the universities, where there was already a bachelor's degree in information technology, as well as a computer class in the majority of the scientific and technological degree programs. Young teachers who had studied computer science in their university phase were gradually incorporated into primary and secondary education, which led to the appearance of leaders and coordinators in the schools they had joined and constituted the launching pad for progressively changing the attitude of the teaching staff about the use of information technology (IT) in classrooms.

The schools' initial incapacity to carry out this process in an isolated way gave rise to policies by both the national government and the regional governments with autonomy in educational matters for the development of information technologies in primary and secondary schools. Previously, an OECD report had been published pointing out Spain's delay compared to other OECD countries, and encouraging the government to develop policies to promote the new technologies.

\section{Governmental Plans to Promote Information Technologies}

The new political situation in Spain influenced the way IT was incorporated into the educational system. Aware of the need to plan the transition to IT use in an orderly way, people in charge of education from the central government and from the six regions with competence in education agreed to work together on this matter, although each institution would independently manage the implantation in its own region. Thus, even though they all had similar objectives, seven parallel projects were developed with different names and plans, which were the following:

- The Atenea Project, developed by the Education Ministry and implanted in the 11 regions that did not have their own educational competences.

- Program of educational computer science Project, developed in Catalonia.

- The Abrente and Estrela Project, developed in Galicia.

- The CERED Project, developed in the Basque Country.

- The Zahara Project, developed in Andalusia.

- The Ábaco Project, developed in the Canary Islands.

- The Programa Informática a l'enseyament Project, developed in the Valencian Community.

All of these projects lasted from four to six years, up until the beginning of the 1990s. In the first half of this decade, a new educational system was implanted in Spain, which meant the attention was focused on the new model and its implications for teaching and evaluation methodologies. This change absorbed the majority of the financial and human resources. Thus, during the first half of the 1990s, once the projects for implanting IT in schools had ended, a new stage began that was 
characterized by the scant involvement of the educational authorities in this area. Moreover, there was a generalized feeling that IT was not a miraculous tool that would change teaching and learning methods, leading to certain pessimism about it (Area, 2008). In the second half of the 1990s, with the rise of the Internet, plans for developing IT in primary and secondary schools were revived, although this time with the objective of making the information society reach the educational setting.

The aforementioned projects shared common traits because, among other reasons, they were experimental projects with which there was no prior experience, and there was a high level of contact between the teams responsible for the different programs. One generalized characteristic of all of them was the elaboration of educational software through calls for participation directed to companies and the teachers themselves, who shared the modules they developed through calls or competitions with other colleagues. The educational software developed largely corresponded to the specific needs of each autonomous community. In some cases, it had a politically influenced bias due to an attempt to highlight historical or linguistic circumstances that differentiated some regions from others.

It can be concluded that the common denominator of all these policies was that they were projects with a Top-Down approach. In a country where the majority of the population did not have direct contact with computers, and the percentage of homes with a computer was insignificant, the priority was to make the students familiar with a new reality through the use of computers in primary and secondary schools. Then, as a result of this experience, their parents, sensitive to the importance of having tools to facilitate their children's learning, would gradually acquire these devices for domestic use.

The following paragraphs describe three of the aforementioned projects. The first project described had the greatest territorial extension, as it affected a large number of schools and teachers. The second project was developed in the Canary Islands, a group of islands that lies more than 1000 kilometers from the peninsular territory and is characterized by a broad territorial dispersion and, at that time, a lower income per capita than the national average. Finally, the initiative developed in Catalonia is described, as it is a region that has a greater income per capita than the Spanish average. Due to its proximity to other European countries, innovations are traditionally carried out sooner in Catalonia than in the rest of the Spanish regions.

\subsection{The Atenea Project}

Of all the projects for incorporating IT, the one that mobilized most resources and had the greatest repercussions was the Atenea Project, which, as mentioned above, was launched by the Education Ministry. It was not the first experience involving the use of computers in the primary and secondary education sector in Spain, given that Catalonia and the Basque Country, due to their autonomy in questions of education management, had already developed pioneer experiences, although with limited importance (Zufiaurre, 1994). The experimental phase of the Atenea Project began in 1985 and lasted until 1989. The budget assigned to it reached 37.5 million dollars (referenced to the year 1985). This budget was divided up, devoting 55\% of the total to buying hardware, $25 \%$ to teacher training, and $20 \%$ to teaching materials (Arango, 1985). In its different stages, a total of 2,300 schools participated. The project's 
efforts focused on primary and secondary education, although the latter received a larger investment. Each center participating in the experience was initially given five micro-computers and a main disk unit, as well as printers.

The main objective of the project was to use the computer as a teaching tool for both the teacher and the students, in order to foster the teaching and learning efforts in both. A secondary objective was to use computers to manage the primary or secondary school. Over time this latter area was where computers' usefulness in the educational sector would be noted most, much more than in the improvements obtained in pedagogical innovation. However, the priority was always to foment the use of computers as an instrument for student learning and spread IT's utility and applications among the members of the school community (García, 2003). The plan created a teacher Responsible for the Atenea project in each center. This teacher received intensive training in the use of the computer and was responsible for training the rest of the teachers in the school in two stages. The first stage provided an initiation in the use of the computer, and another later stage focused on its educational uses.

It should be mentioned that the project was designed with the implicit objective of promoting families' demands for computer devices. Thus, the intention was to favor the national electronic components manufacturing industry, which at that time was in an embryonic stage. The technology adopted in basically all of Spain consisted of compatible IBM-PC computers with an MS-DOS operating system. The adoption of this technology was largely due to the efforts of companies like IBM and others that sell the PC compatible model to introduce it into the Spanish educational sector through donations and very competitive prices, compared to other systems such as the Apple Macintosh. In addition, the conditions for the purchase of the technology by the Education Ministry established that part of the equipment had to be manufactured in Spain, a condition that Apple could not fulfill and that definitively kept it from participating in the project. This situation was completely different from that of the United States, where Apple managed to strongly introduce itself in the educational computer market. In Spain, however, the presence of this type of computers was merely testimonial, with a very small percentage of the market compared to other countries like the United States. Only recently, with the development of the iPad e iPhone platforms, have Apple computers begun to carry some weight in the total computer park in Spain.

\subsection{The Ábaco Project}

The Ábaco project was developed in the Canary Islands, which form an archipelago where a stable population of 1.5 million inhabitants (INE, 1986) lived in the mid1980s. The islands are located about 1400 kilometers from the European continent, across from the western coast of Africa. Until the 1960s, the main economic activities consisted of agriculture and commerce, gradually relinquishing the main role to tourism as the most important economic activity due to the development of commercial airlines. Therefore, the per capita income of the inhabitants of the islands has traditionally been lower than the national average. The low economic development, the distance from the continent, and the fragmentation of the territory on seven islands have been strong obstacles to the development of educational 
policies. With the democratic transition and a higher level of self-government, innovative educational programs that contemplated the particular socio-economic conditions of the region could be put into effect.

The Ábaco program was one of the pioneers in the Spanish ambit, beginning in 1984 and lasting until 1991. Initially, the experience was only extended to six centers in which expert personnel in IT and in psycho-education participated as the teachers. The training took place outside work hours. In each school, a computer room was created, and teachers from two other observer schools were invited to follow the project. The objective was to gradually increase the reach of the experience in an experimental phase, in order to study the effects that introducing computers in schools would have on the learning process. Once the experimental phase had ended, the project was implanted on a large scale in primary and secondary schools in the region (Fernández, 2001).

\subsection{The Educational Computer Program}

This project was developed in Catalonia from the year 1986. Catalonia is a region situated in the extreme northeast of the Iberian Peninsula, bordering France, and it is traditionally the Spanish region that has absorbed the most European influence and has a strong tradition of being the pioneer in adopting new socio-economic tendencies. With a thriving economy based on industry and the services sector, the income per capita is higher than the national average. Catalonia is one of the regions that have most rapidly developed their self-government, due to a historic tradition of a high level of autonomy compared to the rest of the Spanish territories. It is a geographically cohesive territory with good transportation and communications infrastructures.

The educational computer program was initially focused especially on secondary education and then generalized to primary education in 1990. As in the Atenea and Ábaco Projects, the objective was to contribute to improving the learning process and foster the use of the computer as a teaching resource and a means for renovating the educational methodology. The form of implementing the project was also similar in terms of the organization of the personnel. On the one hand, the trainers received intensive training and were freed from their teaching duties to dedicate all their time to the project. On the other hand, the teaching staff in general received courses of varying lengths depending on whether they were only to become computer literate or if there was a commitment by the teacher to use the computer as a teaching tool. The management of the project was performed through a set of specialist teachers distributed throughout territorial areas who had monthly meetings with the teachers in charge of classrooms in all the secondary schools in their territorial areas (Fernández, 2001).

\section{Evaluation of the Projects}

A key question in the development of these projects was the evaluation of the results in relation to the objectives proposed. As these initiatives were promoted by different 
autonomous communities in which the ruling governments were from different political parties, the institutional evaluation was not without a certain bias, as in many cases there was a prevailing interest in offering an image of success that did not exactly correspond to reality. The tendency to carry the political debate to all the areas, including education, meant that some of the evaluation reports elaborated were not completely believable, and in some cases showed true signs of being political propaganda. It should be noted that in Spain there has never been a state agreement that would assure the continuity of the educational model in the long term, regardless of the political party governing at any given time. However, with the perspective of time, it is possible to perform a more objective analysis of the results obtained in the period of time considered.

Thus, the Atenea Project, the largest of those undertaken in Spain during the 1980s, underwent three evaluations, the first two external and the last internal one carried out recently. The first analysis was performed by a team of evaluators from the University of Murcia in 1989. The evaluation concluded that the objective of providing the schools with information technology and increasing the teachers' acceptance of this technology had been reached. However, it showed that the improvement in the pedagogical processes was practically non-existent, and that there was no evidence that computers had the capacity to positively influence the teaching-learning process. This first report was not accepted by the national education authority, which considered that it offered a very negative image of the project. In order to have a second evaluation of the experience, a group of experts from the OECD was asked to elaborate a second report, also in 1989. This report, in contrast, praised the educational authority, highlighting the strong points of the project, so that this evaluation has been considered a political guarantee of the performance of the Education Ministry (García, 2003).

At this point, it is worthwhile to mention an event that influenced the recent history of Spain, its full incorporation into the European Union (EU). The official entry in the EU occurred in 1986. From that moment on, Spain began to carry out common actions with the rest of the countries in the Union, beginning with agricultural, industrial and, even, educational policies, whose high point was the creation of the European Framework for Higher Education in 1998. One of the most noteworthy manifestations of Spain's entrance in the EU was the influx of large amounts of communitarian capital mainly for investments in infrastructures. This influx of capital was due to the low levels of income per capita of many Spanish regions compared to the European mean. The EU, in order to promote equal conditions among all the citizens of the member countries, has a mechanism of structural funds for investment in those countries with a deficit in infrastructures. For this reason, important amounts of money could be used to buy computers, which made it possible for the chapter of purchasing computer equipment to be undertaken. Thus, one of the great problems detected in the phase prior to the development of the projects for incorporating IT in schools was solved, the scarcity of material resources (computers and rooms prepared for their use).

However, it can be stated that the greatest development was achieved in the area of educational management, as computers were incorporated in school administrations to 
support bureaucratic functions, such as managing students' grades, planning timetables for classes, making class lists and assigning students to groups of teachers, etc. In this context, computers at that time had more influence in the administration than in educational innovation and improving the teaching-learning process (Area, 2008).

In all of these projects, the main actors were the primary and secondary school teachers, who were given most of the responsibility for transforming the educational methods. All of the evaluations carried out on the different projects coincide in the lack of teacher training. Some reasons mentioned to explain this deficiency were (Cabero, 1989): (a) scarcity of computers in schools and for teacher training, which affected teachers' lack of familiarity with them; (b) tendency toward immobility with initial rejection of any new technology or teaching strategy; (c) lack of specialists in training trainers; (d) inexistence of training models adapted to the needs of the teacher training field; and (e) high costs of computer training, which involved not only the availability of devices and specific training for teachers, but also computers in an adequate proportion for their use by the students.

\section{The Stage after the Implantation of Projects Incorporating IT in Schools}

The 1990s were characterized by a certain absence of policies for incorporating IT in education. The reason may have been the concentration of efforts in adapting primary and secondary schools to the new education planning and development law (LOGSE), which meant a strong change in the teaching-learning procedures, the evaluation and management of the schools, and the schools' interrelation with the society. In addition, there was also a feeling that computers had not been the prodigious tool that would revolutionize the teaching and learning methods, so that it seemed that computers' potential had practically reached its limit.

In these circumstances, during this decade there was a boom in Internet as a global tool for dealing with large amounts of information. The impact of the Internet, not only on companies but also on citizens, gave rise to an unusual tendency toward buying computers for the home. From that moment on, there was an inversion in the process of incorporating computers into the schools, going from a Top-Down to a Bottom-Up sequence. In this process, familiarity with the use of computers created what have been called digital natives, children and young people with skills in the use of IT. They have been a great challenge to the schools, as a large part of the teaching staff does not dominate the technology with the same ability as the students they teach. This situation creates educational dysfunctions that are currently being studied.

In the second half of the 1990s, programs to incorporate information technologies proliferated again, but this time with the addition of communication, with the term information and communication technology (ICT) becoming popularized. This boom was due to the spectacular development of the Internet and the growing weight of governmental policies in favor of developing the information society. Two examples would be the National Information Infrastructure Plan, promoted by Vice-president Al 
Gore in the United States in the 1990s, and the Lisbon Strategy in Europe in the year 2000. It is important to indicate that in this period the different Spanish regions developed their autonomy in matters of education under the 1978 Constitution, with the figure of the Education Ministry remaining as a merely legislative organism, leaving the development of educational innovation policies to the different regions. Therefore, numerous programs were developed of an exclusively regional ambit (Averroes in Andalusia, Medusa in the Canary Islands, Premia in the Basque Country, Ramón y Cajal in Aragón, Plumier in Murcia, Siega in Galicia, Argo in Catalonia, etc.), without any institutional coordination at the national level or among the different regions on this occasion. Nor were forums for meeting or collaboration developed that would serve to share experiences and coordinate the integration of ICT in the Spanish educational system in line with worldwide tendencies or European guidelines (Sanabria \& Area, 2011).

\section{Conclusions}

The history of computers in education in Spain has been closely linked to the political avatars that characterized the history of Spain from the end of the 1970s to the beginning of the 1990s. During this time, the secular delay in the country's economy and education was made evident by the fact that the incorporation of computers in the educational setting was already a reality in other developed countries. The frictions between the different autonomous communities that make up the national geography gave rise to actions with a more political tone than educational. This was partly due to the fact that the autonomous communities, with their own deeply-rooted historical references, gave rise to the emergence of a territorial model that was not exempt from a certain degree of hurry. The entrance into the European Union in 1986, and with it the contribution of European funds for the cohesion among the different European regions, created the possibility of making strong investments in information technology, with which they could achieve, at the least, the objective of having computer rooms in the majority of schools at the end of the 1980s.

The initial enthusiasm and consideration that computers were going to produce a radical change in the teaching-learning process was giving way to a feeling of deception because very little had actually changed. This perception produced certain skepticism about the usefulness of computers in primary and secondary schools, so that governmental actions supporting the incorporation of IT in schools diminished significantly at the beginning of the 1990s. However, the true driving force that allowed a certain balance between the IT infrastructure in Spain and that of other OECD countries was the phenomenon of the information society, which has become deeply integrated in Spanish society and really caused the inversion in the order of the process. Today ICT can be considered an integral part of the educational process, even though the Copernican revolution that was expected with the incorporation of computers in schools never took place. 


\section{References}

1. Arango, J.: El proyecto Atenea: Un plan para la introducción nacional de la informática en la escuela. Revista de Educación 276, 5-25 (1985)

2. Area, M.: Una breve historia de las políticas de incorporación de las tecnologías digitales al sistema escolar en España. Quaderns Digitals 51 (2008)

3. Cabero, J.: La formación del profesorado en medios audiovisuales. El Siglo que Viene 4(5), 14-19 (1989)

4. Fernández, M.S.: Las nuevas tecnologías en la educación: análisis de modelos de aplicación. UAM, Madrid (2001)

5. García, E.: La evaluación de programas de reforma educativa en España: tres estudios de caso desde un enfoque de metaevaluación. Doctoral Thesis. Universidad Complutense de Madrid (2003)

6. INE-Instituto Nacional de Estadística: Padrón de habitantes (1986)

7. Saez, J.M.: Apple pretende conseguir en España el éxito alcanzado en Europa y América. ABC Económico, 4 marzo, 40 (1985)

8. Sanabria, A.L., Area, M.: Las políticas educativas para incorporar las TIC al sistema escolar en Canarias. De Ábaco a ClicEscuela 2.0. In: Roig, A., Laneve, C. (eds.) La práctica educativa en la Sociedad de la Información: Innovación a través de la investigación, pp. 369-382 (2011)

9. Zufiaurre, B.: Proceso y contradicciones de la reforma educativa, pp. 1982-1994. Icaria, Barcelona (1994) 